\title{
PENGARUH IDENTITAS MEREK, CITRA MEREK, DAN KEPERCAYAAN MEREK TERHADAP LOYALITAS MEREK PADA RUMAH MAKAN WAROENG SPESIAL SAMBAL "WAROENG SS" CABANG PASAR LAMA KOTA TANGERANG
}

\author{
Oktaviasari \\ oktaviasari446@gmail.com \\ Fakultas Ekonomi dan Bisnis Universitas Islam Syekh Yusuf Tangerang \\ Hadi Suharno \\ hsuharno@unis.ac.id \\ Fakultas Ekonomi dan Bisnis Universitas Islam Syekh Yusuf Tangerang \\ Umi Kulsum \\ ukulsum@unis.ac.id \\ Fakultas Ekonomi dan Bisnis Universitas Islam Syekh Yusuf Tangerang
}

\begin{abstract}
This research was done to analyze the effect of variable $(X I)$ brand identity to the variable $(Y)$ that is brand loyalty, the influence of variables $(X 2)$ is the brand image to variable $(Y)$ that is brand loyalty, the influence of variables $(X 3)$ is brand trust the to variable $(Y)$ that is brand loyalty, and the effect of variable $(X I)$ which is variable brand identity, variable $(X 2)$ is the brand imageand variabel $(X 3)$ is the brand trustsimultaneously to variable (Y) brand loyalty. This research was conducted using a survey method. The population in this study is that consumers Rumah Makan Waroeng Spesial Sambal Waroeng SS Cabang Pasar Lama Kota Tangerang. Sampling with 100 respondents conducted by incidental sampling technique. While the analysis is done is done with the data, the classic assumption test hypothesis testing, validity, reliability, multiple regression analysis, multiple correlation analysis, and analysis of the coefficient of determination $\left(R^{2}\right)$. Based on data analysis performed in this study, it can be concluded that the variable $(X I)$ quality of service and significant positive effect on the variable $(Y)$ is $38 \%$ of customer retention. Variable $(X 2)$ is the brand image and significant is not positive effect on the variable $(Y)$ is $36 \%$ of brand loyalty,Variable (X3) is the brand trust and significant positive effect on the variable $(Y)$ is $56 \%$ of brand loyalty. F-count value is greater than the value of I2,382 F-table is 3.09 . So Ho rejected and $\mathrm{Ha}$ accepted. The rest was influenced by other variables not examined in this study.
\end{abstract}

Keywords: Brand Identity, Brand Image, Brand Trust, Brand Loyalty.

\section{A. PENDAHULUAN}

Dizaman era globalisasi telah berkembangnya usaha rumah makan, banyak orang-orang yang sulit mendapatkan pekerjaan, dan dari mereka yang mencoba untuk membuka usaha sendiri, atau wirausahawan. Salah satunya yaitu usaha rumah makan. Bisnis rumah makan merupakan usaha yang sejak dulu sampai saat ini memang terus berkembang tidak pernah surut bahkan mengikuti zaman yang semakin maju.

Waroeng Spesial Sambal "Waroeng SS" pada cabang Pasar Lama Kota Tangerang memiliki tagline "Pedes Gila" adalah rumah makan yang memiliki unsur yang menyajikan aneka sambal segar dan makanan khas untuk lidah Indonesia. Waroeng Spesial Sambal "Waroeng SS" cabang Pasar Lama Kota Tangerang inilah perusahaan rumah makan memberikan perhatian khusus terhadap indentitas merek agar konsumen selalu mengingat dalam memorinya. Identitas merek adalah seperangkat asosiasi merek yang unik yang diciptakan oleh para penyusun stategi merek.

salah satunya dengan membentuk citra merek yang kuat oleh perusahaan rumah makan yang sudah dibangun selama ini. Tanpa adanya citra merek yang kuat dan positif, sangatlah sulit bagi perusahaan untuk menarik pelanggan baru dan mempertahankan yang sudah ada. Munculnya berbagai macam rumah makan dengan mempunyai satu kategori dengan kualitas yang baik dan sudah menjadi standar dan dapat 
dengan mudah ditiru dan dimiliki oleh siapapun megakibatkan sulitnya suatu perusahaan untuk mempertahankan dirinya sebagai pemimpin pasar.

Kepercayaan merek dari pihak konsumen sangat penting di harapkan bagi pengusaha rumah makan dari kepercayaan merek tersebut konsumen bisa menilai rumah makan yang memiliki kualitas yang baik yang menimbulkan reaksi yang positif bagi si pengusaha rumah makan atau sebaliknya menimbulkan reaksi yang negatif. Membangun Kepercayaan merek dari konsumen dengan terus berinovasi dengan menambahkan menu baru untuk memuaskan harapan dari konsumen.

Hubungan antara identitias merek, citra merek, dan kepercayaan merek terhadap loyalitas merek mampu memiliki harapan konsumen atau bahkan memberikan jaminan kualitas pada setiap kesempatan penggunanya serta merek akan mudah dibentuk hubungan yang sangat positif untuk rumah makan Waroeng Spesial Sambal "Waroeng SS" pada cabang Pasar Lama Kota Tangerang membuktikan bahwa konsumen akan berdatangan secara berulang dan konsisten dalam memilih.

\section{Pengertian Identitas Merek}

Identitas sering diartikan sebagi ciri-ciri yang melekat pada suatu objek sehingga membedakannya dengan yang lain. Misalnya, bisa dikenali denga cepat Karena ciri-ciri yang dimilikinya. Agar dapat berfungsi sebagai pembeda yang tegas, sebuah cirri haruslah khas alias tidak umum.

Menurut (Keller, 20I4) Bagi sebuah merek, "memiliki identitas yang tegas adalah sesuatu yang sangat berharga ditengah ratusan, bahkan ribuan produk yang setiap saat membanjiri pasar".

\section{Pengertian Citra Merek}

Citra merek adalah pemahaman pelanggan mengenai merek secara keseluruhan dan bagaimana pelanggan memandang suatu merek yang positif.

Menurut Ramadhoni (2015) citra merek meripakan serangkaian asosiasi (persepsi) yang ada dalam benak konsumen terhadap suatu merek, biasanya terorganisasi menjadi suatu makna.

\section{Pengertian Kepercayaan Merek}

Kepercayaan merek adalah sudut pandang konsumen dengan merek tersebut dan rasa percaya pada merek, kepuasan, pengalaman, dan penggunaan secara langsung dan tidak langsung dengan merek serta memberikan hasil yang positif kepada konsumen sehingga akan menimbulkan kesetiaan terhadap suatu merek.

Menurut Warusman dan Untarini (2016:36), “kepercayaan merek merupakan suatu nilai merek yang dapat diciptakan melalui beberapa aspek yang dapat menimbulkan kepuasan konsumen, dimana setiap individu pada konsumen menghubungkan kepercayaan merek dengan pengalaman pada merek tersebut".

\section{Pengertian Loyalitas Merek}

Loyalitas merek merupakan sikap positif dan kelekatan seorang konsumen pada sebuah merek. Yaitu konsumen memilih untuk membeli merek tertentu dibandingkan merek lain dalam satu kategori produk secara konsisten.

Menurut Kotler dan Amstrong (2015:49) "Loyalitas merek adaah menjaga pelanggan yang loyal menggunakan produk perusahaan lebih banyak dan dalam waktu yang lebih lama. Kehilangan pelanggan yang loyal dapat berarti kehilangan aliran pendapatan pelanggan tersebut diwaktu yang akan datang". 


\section{HIPOTESIS}

\section{Gambar I : Kerangka Penelitian}

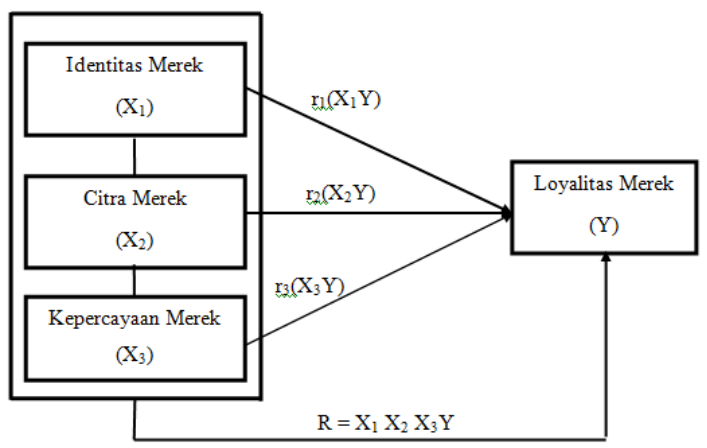

(Sumber: Sugiyono, 2017)

$\mathrm{Ha}_{\text {। }}$ : Dari hasil penelitian yang diteliti benar dan sesuai dengan hasil dugaan diatas yaitu karena terdapat pengaruh yang positif dan signifikan antara identitas merek terhadap loyalitas merek.

$\mathrm{Ha}_{2}$ : Dari hasil penelitian yang diteliti benar dan sesuai dengan hasil dugaan diatas yaitu karena terdapat pengaruh yang positif dan tidak signifikan antara citra merek terhadap loyalitas merek.

$\mathrm{Ha}_{3}$ : Dari hasil penelitian yang diteliti benar dan sesuai dengan hasil dugaan diatas yaitu karena terdapat pengaruh yang positif dan tidak signifikan antara kepercayaan merek terhadap loyalitas merek.

$\mathrm{Ha}_{4}$ : Dari hasil penelitian yang diteliti benar dan sesuai dengan hasil dugaan diatas yaitu karena terdapat pengaruh yang positif dan signifikan antara identitas merek, citra merek, dan kepercayaan merek terhadap loyalitas merek.

\section{B. METODE PENELITIAN}

Dalam penelitian ini metode yang peneliti gunakan adalah metode kuantitaf dengan teknik atau cara mencari, memperoleh, menyimpulkan atau mencatat data primer dan data sekunder yang digunakan untuk keperluan menyusun suatu karya ilmiah dan kemudian menganalisa yang berhubungan dengan pokok permasalahan sehingga akan terdapat suatu kebenaran data yang diperoleh. Penelitian ini menggunakan metode penelitian asosiatif kausal.

\section{Populasi}

Menurut Saiful Bahri (2017) "Populasi adalah keseluruhan objek penelitian dan memenuhi obyek/subyek yang mempunyai kualitas dan karakteristik tertentu yang ditetapkan oleh penelitian untuk dipelajari dan kemudian ditarik kesimpulannya".

Jadi populasi dalam penelitian ini adalah pelanggan rumah makan Waroeng Spesial Sambal "waroeng SS" cabang pasar lama Kota Tangerang.

\section{Sampel}

Berdasarkan pada penelitian ini dengan populasi yang tidak terduga maka untuk pengambilan sampel peneliti mengambil 100 jumlah sampe yang digunakan pada rumah makan Waroeng Spesial Sambal "waroeng SS" cabang pasar lama Kota Tangerang. Untuk pengambilan sampelnya itu penulis menggunaka teknik sampel Peneliti menggunakan sampel secara Random (probability sampling). Menurut Saiful Bahri (2018) probability sampling adalah teknik pemilihan sampel berdasarkan peluang untuk setiap respoden atau acak untuk dijadikan anggota sampel.

Dalam penelitian ini untuk pengambilan dapat dilakukan secara sampel berdasarkan kemudahan accidante sampling yaitu merupakan teknik pemilihan sampel secara random atau kebetulan saja karena teknik sampel ini sangat mudah, cepat dan murah tetapi hasil penelitiannya kadang kurang memuaskan karena sampel mudah. 


\section{Metode Analisis Data Uji Asumsi Klasik}

\section{Uji Normalitas}

Uji Normalitas data adalah uji distribusi data yang akan di analisis untuk penyebarannya dibawah kurva normal atau tidak.

Untuk uji residual dengan metode grafik normal P-P Plot of regression standardized residual sebagai dasar pengambilan keputusan $\mathrm{HO}$ : Data residual berdistribusi normal dan $\mathrm{Ha}$ : Data residual tidak berdistribusi normal.

Untuk Uji One-Sampe Kolmogorov-Smirnov apabila nilai Asymp.Sig(2-tailed) dengan variabel residual berada di atas 0,05 atau 5\%, dan sebaliknya jika nilai Asymp.Sig(2-tailed) dengan variabel residual berada di bawah 0,05 atau $5 \%$, maka data tersebut tidak berdistribusi normal atau tidak memenuhi uji normalitas.

\section{Uji Multikolonieritas}

Uji Multikolineritas untuk menguji model regresi ditemukan adanya kolerasi antarvariabel independen (Saiful Bahri, 2018:168).

Model regresi yang baik seharusnya tidak terjadi korelasi diantara variabel independen. Uji multikolonieritas dalam penelitian ini dilakukan dengan melihat nilai tolerance (TOL) dan variabel inflation factor (VIF).

Kriteria pengambilan keputusan pada uji multikolonieritas adalah jika nilai tolerance $<0$.I atau sama dengan $>10$ menunjukkan adanya multikolonieritas. Sedangkan, jika nilai tolerance $>0.1$ atau sama dengan nilai $\mathrm{VIF}<10$ maka bebas multikolinieritas.

\section{Uji Heteroskedastisitas}

Menurut (Saiful Bahri, 2018:182) "Uji Heteroskedastisitas adalah bertujuan menguji apakah model regresi terjadi ketidaksamaan varians dari residual satu pengamatan ke pengamatan lain". Heteroskedastisitas adalah variabel residual yang tidak sama pada semua pengamatan di dalam model regresi. Apabila regresi yang baik seharusnya tidak terjadi heteroskedastisitas.

\section{Analisis Model Regresi Liner Berganda}

Menurut Suntoyo (2014:139) "Analisis regresi merupakan analisis yang digunaka untuk mengukur sejauh mana pengaruh satu atau beberapa variabel bebas terhadap variabel terikat, baik parsial maupun simultan".

Variable bebas disimbolkan $\mathrm{X}$ dan variable terikat disimbolkan $\mathrm{Y}$. Analisis regresi berganda untuk mengetahui pengaruh dua atau lebih variable bebas terhadap variable terikat.

\section{Analisis Model Koleraasi Berganda}

Analisis korelasi adalah Analisis yang bertujuan untuk mengetahui kuat atau tidaknya hubungan yang terjadi antara variable bebas dengan variabel terikat baik berganda maupun parsial.

\section{Uji Statistik T}

Ketetapan fungsi sampel dalam menaksir nilai actual dapat diukur dari goodness of fit nya. Secara statistik, setidaknyaini dapat diukur dari nilai koefisien determinasi, nilai statistik $F$ dan $T$, perhitungan statistic disebut signifikan secara statistik, apabila uji nilai statistiknya berada dalam daerah kritis (daerah dimana Ho ditolak). Sebaliknya, disebut tidak signifikan bila uji nilai statisknya berada dalam daerah dimana Ho diterima.

\section{Uji Statistik F}

Uji $\mathrm{F}$ untuk dapat menguji pada variable bebas (independen) secara bersama-sama terhadap variable terikat (dependen).

\section{Koefisien Determinasi}

Menurut (Saiful Bahri, 2018) “Uji T digunakan untuk menguji hipotesis korelasi sederhana yaitu untuk menguji hubungan masing-masing variable independen secara parsial terhadap variable dependen dengan taraf signifikan sebesar $5 \%$ hipotesis". 


\section{HASIL PENELITIAN}

1. Uji Normalitas

Hasil Uji Normalitas Scatterplot

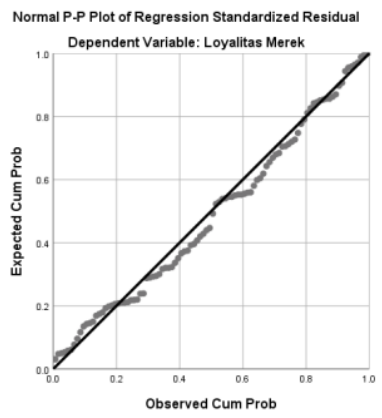

Berdasarkan tampilan normal p-plot regression standarized terlihat bahwa titik titik menyebar disekitar garis diagonal. Oleh karena itu, berdasarkan uji normalitas analisis regresi layak digunakan.

Hasil Pengukuran Uji Normalitas

\begin{tabular}{|c|c|c|}
\hline \multicolumn{3}{|c|}{ One-Sample Kolmogorov-Smirnov Test } \\
\hline & & $\begin{array}{l}\text { Unstandardiz } \\
\text { ed Residual }\end{array}$ \\
\hline \multicolumn{2}{|l|}{$\mathrm{N}$} & 100 \\
\hline \multirow[t]{2}{*}{ Normal Parameters ${ }^{\mathrm{a}, \mathrm{b}}$} & Mean & .0000000 \\
\hline & \begin{tabular}{|l|} 
Std. \\
Deviation
\end{tabular} & 2.52657521 \\
\hline \multirow{3}{*}{$\begin{array}{l}\text { Most Extreme } \\
\text { Differences }\end{array}$} & Absolute & .069 \\
\hline & Positive & .069 \\
\hline & Negative & -.041 \\
\hline \multicolumn{2}{|l|}{ Test Statistic } & .069 \\
\hline \multicolumn{2}{|l|}{ Asymp. Sig. (2-tailed) } & $.200^{\mathrm{c}, \mathrm{d}}$ \\
\hline \multicolumn{3}{|c|}{ a. Test distribution is Normal. } \\
\hline
\end{tabular}

Pengujian Normalitas Kolmogrov Smirnov Test menghasilkan Asymtotic Significance yaitu $0,200>0.05$. Maka hasil data yang di dapat menunjukkan pola distribusi normal, maka dapat disimpulkan memenuhi hasil asumsi normalitas.

2. Uji Multikolonieritas

\begin{tabular}{|c|c|c|c|c|c|c|c|c|}
\hline \multicolumn{9}{|c|}{ Coefficients $^{\mathrm{a}}$} \\
\hline & & \multicolumn{2}{|c|}{$\begin{array}{c}\text { Unstandardized } \\
\text { Coefficients }\end{array}$} & \multirow{2}{*}{\begin{tabular}{c|} 
Standardized \\
Coefficients \\
Beta \\
\end{tabular}} & \multirow[b]{2}{*}{$\mathrm{T}$} & \multirow[b]{2}{*}{ Sig. } & \multicolumn{2}{|c|}{$\begin{array}{l}\text { Collinearity } \\
\text { Statistics }\end{array}$} \\
\hline \multicolumn{2}{|c|}{ Model } & . & $\begin{array}{l}\text { Std. } \\
\text { Error }\end{array}$ & & & & Tolerance & VIF \\
\hline \multirow[t]{4}{*}{\begin{tabular}{|l|l|}
1 \\
\end{tabular}} & \begin{tabular}{|l} 
(Constant) \\
\end{tabular} & 12.410 & 3.422 & & 3.626 & .000 & & \\
\hline & \begin{tabular}{|l|} 
Identitas \\
Merek
\end{tabular} & .227 & .107 & .225 & 2.131 & .036 & .669 & 1.495 \\
\hline & \begin{tabular}{|l} 
Citra Merek \\
\end{tabular} & -.031 & .095 & -.039 & -.324 & 746 & .510 & 1.962 \\
\hline & $\begin{array}{l}\text { Kepercayaan } \\
\text { Merek }\end{array}$ & .395 & .096 & .439 & 4.129 & .000 & .659 & 1.517 \\
\hline
\end{tabular}

Menurut Imam Ghozali (2016), “dalam kriteria pengambilan keputusan pada uji multikolonieritas adalah jika nilai tolerance $<0.1$ atau sama dengan $>10$ menunjukkan adanya multikolonieritas. Sedangkan, jika nilai tolerance $>0.1$ atau sama dengan nilai VIF $<10$ maka bebas multikolinieritas". Dapat diketahui hasil Tolerance dan VIF pada Variabel Identitas Merek (X1) yaitu menunjukan TOL 0,669 > 0,1 dan VIF 1,495 < 10 , lalu pada Variabel Citra Merek (X2) yaitu menunjukan TOL 0,510>0,1 dan VIF 1,962 < 10 , dan Variabel Kepercayaan Merek (X3) yaitu menunjukan TOL 0,659>0,1 dan VIF $1,517<10$. Karena nilai VIF untuk semua Variabel dari X1 sampai X3 tersebut $<10$ dan dapat di simpulkan tidak terjadinya gangguan multikolinearits. 


\section{Uji Heteroskedastisitas}

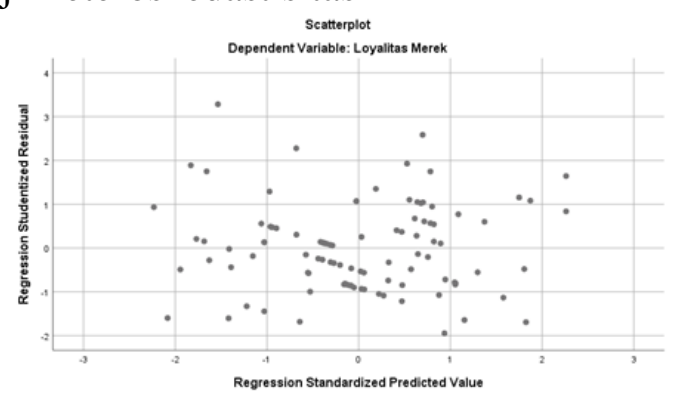

Sumber: Pelanggan Waroeng SS (data primer diolah oleh SPSS 25.0 2019)

Diketahui dapat disimpulkan bahwa pola titik-titik menyebar diatas angka nol pada sumbu $Y$ dan tidak terjadi masalah heteroskedasitas seingga model regresi yang baik dan ideal dapat terpenuhi.

Hasil Regresi Linear Berganda

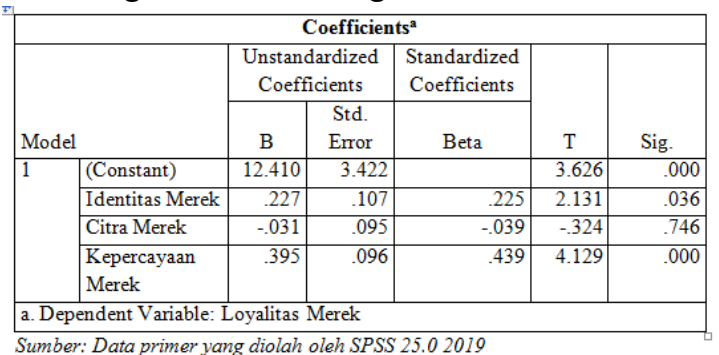

Berdasarkan hasil tabel 4.48 diatas pengujian menggunakan software IBM SPSS 25.0 diatas diketahui maka data dapat dilihat persamaan regresi berganda sebagai berikut :

$Y:|2.4| 0+0,227 X_{1}+0,03 \mid X_{2}+0,395 X_{3}$

Interprestasi persamaan tersebut :

$\mathrm{Y} \quad=$ Loyalitas Merek

$\mathrm{X}_{1} \quad=$ Identitas Merek

$\mathrm{X}_{2} \quad=$ Citra Merek

$\mathrm{X}_{3} \quad=$ Kepercayaan Merek

e $\quad=$ Eror

1. Nilai Konstanta sebesar 0,I2410 menunjukan bahwa pada variabel Identitas Merek (XI), Citra Merek (X2), Kepercayaan Merek (X3) jika nilainya mempunya 0 maka pada variabel Loyalitas Merek (Y) memiliki tingkat Loyalitas Merek (Y) yaitu 0,I24I0.

2. Nilai Koefisien bI pada Variabel $X I$ sebesar 0,227 menunjukan bahwa pada variabel Identitas Merek (XI) meningkat maka variabel Loyalitas Merek (Y) meningkat yaitu 0,227.

3. Nilai Koefisien b2 pada Variabel $X 2$ sebesar -0,3I menunjukan bahwa pada variabel Citra Merek (XI) penurunan satu satuan maka variabel Loyalitas Merek (Y) penurunan satu satuan yaitu $-0,3 \mathrm{I}$.

4. Nilai Koefisien b3 pada Variabel X3 sebesar 0,395 menunjukan bahwa pada variabel Identitas Merek (XI) meningkat maka variabel Loyalitas Merek (Y) meningkat yaitu 0,395. 


\section{Hasil Uji Kolerasi Berganda}

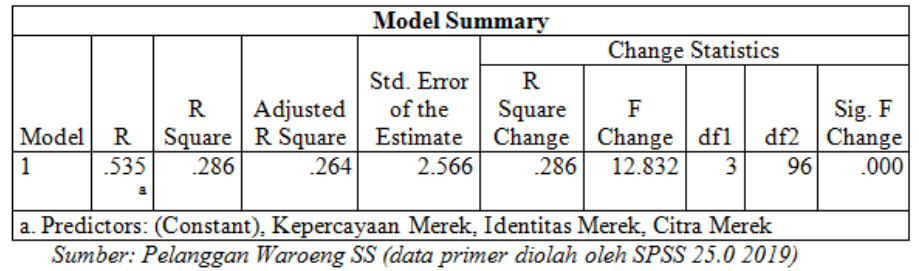

Mengetahui $R=0,535$ atau 53,5\% artinya variabel Identitas Merek $(X 1)$, Citra Merek $(X 2)$, Kepercayaan Merek (X3) memiliki hubungan terhadap variabel Loyalitas Merek (Y) menunjukkan kolerasi positif dan sedang karena nilai kolerasi berada di range 0,40-0,599.

\section{Uji Statistis T parsial Identitas Merek (XI) terhadap Loyalitas Merek (Y)}

\begin{tabular}{|l|l|r|r|r|r|c|}
\hline \multicolumn{7}{|c|}{ Coefficients $^{\mathbf{a}}$} \\
\hline \multirow{2}{*}{ Model } & \multicolumn{2}{|c|}{$\begin{array}{c}\text { Unstandardized } \\
\text { Coefficients }\end{array}$} & $\begin{array}{c}\text { Standardized } \\
\text { Coefficients }\end{array}$ & & \\
\cline { 2 - 7 } & \multicolumn{1}{|c|}{$\mathrm{B}$} & Std. Error & Beta & t & Sig. \\
\hline 1 & (Constant) & 19.727 & 3.281 & & 6.012 & .000 \\
\cline { 2 - 7 } & Identitas Merek & .366 & .095 & .362 & 3.849 & .000 \\
\hline \multicolumn{2}{|l|}{ a. Dependent Variable: Loyalitas Merek } \\
Sumber: Pelanggan Waroeng SS (data primer diolah oleh SPSS 25.0 2019)
\end{tabular}

Melalui perhitungan $\mathrm{T}$ tabel menunjukkan bahwa $\mathrm{T}$ tabel 0,198 , dan $\mathrm{T}$ hitung menunjukkan angka 3,849 maka 3,849 > 0,198, yang berarti ada pengaruh namun Positif. Dengan demikian, hasil uji parsial Identitas Merek (XI) berpengaruh positif dan signifikan terhadap Loyalitas Merek, sehingga $\mathrm{HO}$ ditolak $\mathrm{Ha}$ diterima.

\section{Uji Statistis T parsial Citra Merek (X2) terhadap Loyalitas Merek (Y)}

\begin{tabular}{|c|c|c|c|c|c|c|}
\hline \multicolumn{7}{|c|}{ Coefficients $^{\mathrm{a}}$} \\
\hline & & \multicolumn{2}{|c|}{$\begin{array}{l}\text { Unstandardized } \\
\text { Coefficients }\end{array}$} & \multirow{2}{*}{$\begin{array}{c}\text { Standardized } \\
\text { Coefficients } \\
\text { Beta } \\
\end{array}$} & \multirow[b]{2}{*}{$\mathrm{T}$} & \multirow[b]{2}{*}{ Sig. } \\
\hline \multicolumn{2}{|c|}{ Model } & $\mathrm{B}$ & \begin{tabular}{|l|} 
Std. Error \\
\end{tabular} & & & \\
\hline \multirow[t]{2}{*}{1} & (Constant) & 22.196 & 2.790 & & 7.956 & .000 \\
\hline & Citra Merek & .271 & .074 & .345 & 3.644 & .000 \\
\hline
\end{tabular}

Sumber: Pelanggan Waroeng SS (data primer diolah oleh SPSS 25.0 2019)

Melalui perhitungan $\mathrm{T}$ tabel menunjukkan bahwa $\mathrm{T}$ tabel 0,198, dan $\mathrm{T}$ hitung menunjukkan angka 3,644 maka 3,644 > 0,196, yang berarti ada pengaruh Positif. Dengan demikian, hasil uji parsial Citra Merek (X2) berpengaruh positif dan berpengaruh signifikan terhadap Loyalitas Merek, sehingga H0 ditolak Ha diterima.

\section{Uji Statistis T parsial Kepercayaan Merek (X3) terhadap Loyalitas Merek (Y)}

\begin{tabular}{|l|l|r|r|r|r|r|}
\hline \multicolumn{7}{|c|}{ Coefficients $^{\mathbf{2}}$} \\
\hline \multirow{2}{*}{ Model } & \multicolumn{2}{|c|}{$\begin{array}{c}\text { Unstandardized } \\
\text { Coefficients }\end{array}$} & $\begin{array}{c}\text { Standardized } \\
\text { Coefficients }\end{array}$ & & \\
\cline { 2 - 5 } & \multicolumn{1}{|c|}{ B } & Std. Error & Beta & t & Sig. \\
\hline \multirow{2}{*}{1} & (Constant) & 17.277 & 2.658 & & 6.499 & .000 \\
\cline { 2 - 6 } & Kepercayaan Merek & .449 & .079 & .498 & 5.682 & .000 \\
\hline \multicolumn{2}{|l|}{ a. Dependent Variable: Loyalitas Merek } \\
Sumber: Pelanggan Waroeng SS (data primer diolah oleh SPSS 25.0 2019)
\end{tabular}

Melalui perhitungan $\mathrm{T}$ tabel menunjukkan bahwa $\mathrm{T}$ tabel 0,198, dan $\mathrm{T}$ hitung menunjukkan angka 5,682 maka 5,682 >0,198, yang berarti ada pengaruh namun Positif. Dengan demikian, hasil uji parsial Kepercayaan Merek (X3) berpengaruh positif dan signifikan terhadap Loyalitas Merek (Y), sehingga sehingga $\mathrm{HO}$ ditolak $\mathrm{Ha}$ diterima. 
Hasil Uji Statistis F Simultan

\begin{tabular}{|c|c|c|c|c|c|c|}
\hline \multicolumn{7}{|c|}{ ANOVA $^{\text {a }}$} \\
\hline \multicolumn{2}{|c|}{ Model } & $\begin{array}{l}\text { Sum of } \\
\text { Squares }\end{array}$ & Df & Mean Square & F & Sig. \\
\hline \multirow[t]{3}{*}{1} & Regression & 253.415 & 3 & 84.472 & 12.832 & $.000^{\mathrm{b}}$ \\
\hline & Residual & 631.975 & 96 & 6.583 & & \\
\hline & Total & 885.390 & 99 & & & \\
\hline \multicolumn{7}{|c|}{ a. Dependent Variable: Loyalitas Merek } \\
\hline \multicolumn{7}{|c|}{ b. Predictors: (Constant), Kepercayaan Merek, Identitas Merek, Citra Merel } \\
\hline
\end{tabular}

Sumber: Pelanggan Waroeng SS (data primer diolah oleh SPSS 25.0 2019)

Diketahui bahwa F - hitung yaitu 12, 832 .> F - tabel 0,39 atau nilai sig. yaitu 0,000< $(\alpha) 0,05$ Maka Ho di Tolak dan Ha di Terima yang berarti terdapat hubungan yang positif dan signifikan antar Identitas Merek(XI). Citra Merek (X2), Kepercayaan Merek (X4) terhdap Loyalitas Merek (Y).

Hasil Uji Koefisien Determinasi

\begin{tabular}{|l|l|r|r|c|}
\hline \multicolumn{5}{|c|}{ Model Summary } \\
\hline Model & $\mathrm{R}$ & R Square & $\begin{array}{c}\text { Adjusted R } \\
\text { Square }\end{array}$ & $\begin{array}{c}\text { Std. Error of } \\
\text { the Estimate }\end{array}$ \\
\hline 1 & $.535^{\mathrm{a}}$ & .286 & .264 & 2.566 \\
\hline $\begin{array}{l}\text { a. Predictors: (Constant), Kepercayaan Merek, Identitas } \\
\text { Merek, Citra Merek }\end{array}$ \\
Sumber: Pelanggan Waroeng SS (data primer diolah oleh SPSS 25.0 2019)
\end{tabular}

Diketahui pada nilai Adjusted $R$ Square sebesar 0,264 atau 26,4\% artinya mempunyai kemampuan variabel bebas dalam menjelaskan setiap variabel pada variabel terikat adalah sebesar 26,45 . Adapun faktor lain mempunyai Loyalitas Merek adalah :

$$
\begin{aligned}
& \text { Knd }=(1-0,264) \times 100 \% \\
& \text { Knd }=(0,736) \times 100 \%
\end{aligned}
$$

Artinya ada faktor lain yang mempunyai Loyalitas Merek sebrsar 0,736 atau 73,6\%. Faktor lain ini yang dimaksud tidak diteliti dalam penelitian ini.

\section{KESIMPULAN DAN SARAN}

Berdasarkan dari penelitian yang telah dilakukan di Rumah Makan Waroeng Spesial Sambal "Waroeng SS" Cabang Pasar Lama Kota Tangerang tentang Identitas Merek, Citra Merek, dan Kepercayaan Merek Terhadap Loyalitas Merek Rumah Makan Waroeng Spesial Sambal "Waroeng SS" Cabang Pasar Lama Kota Tangerang.. Telah menguraikan dari bab I tentang latar belakang, identifikasi masalah, perumusan masalah dan bab II membahas tentang landasan teori yang memuat tentang pedapat dari para pakar dan diteruskan dengan bab III tentang metode penelitian dengan populasi dan sample dalam pengumpulan data dengan instrument indicator penelitian yang teratur serta metode analisa pembahasan data yang sistematis. Sehingga penulis dapat memberikan kesimpulan pada hasil penelitian di bab IV sebagai berikut:

I. Pada Uji T parsial Terdapat pengaruh positif dan signifikan antara Identittas Merek (XI) Terhadap Loyalitas Merek (Y) rumah makan Waroeng Spesial Sambal "Waroeng SS" Cabang Pasar Lama Kota Tangerang. Dengan mempunyai nilai signifikan $0.000>0,05$ dan mempunyai nilai $\mathrm{T}$ hitung sebesar 3,849 > T tabel sebesar 0, 198 Maka $\mathrm{Ho}$, di tolak dan $\mathrm{Ha}$, di terima

2. Pada Uji T parsial Terdapat tidak berpengaruh positif dan tidak signifikan antara Cita Merek (X2) Terhadap Loyalitas Merek (Y) rumah makan Waroeng Spesial Sambal "Waroeng SS" Cabang Pasar Lama Kota Tangerang. Dengan mempunya nilai signifikasi 0,000 $>0,05$ dan mempunyai $\mathrm{T}$ hitung sebesar 3,644 > T tabel sebesar 0, 198 Maka $\mathrm{Ho}_{2}$ di Tolak dan $\mathrm{Ha}_{2}$ di Terima

3. Pada Uji T parsial Terdapat pengaruh positif dan signifikan antara Kepercayaan Merek (X3) Terhadap Loyalitas Merek (Y) rumah makan Waroeng Spesial Sambal "Waroeng SS” Cabang Pasar 
Lama Kota Tangerang. Dengan mempunyai nilai signifikan $0.000>0,05$ dan mempunyai nilai $T$ hitung sebesar 5,682 > T tabel sebesar 0, $196 \mathrm{Maka} \mathrm{Ho}_{3}$ di Tolak dan $\mathrm{Ha}_{3}$ di Terima.

4. Pada Uji F simultan terdapat berpengaruh secara simultan anta variabel Identitas Merek, Citra Merek, Kepercayaan Merek terhadap Loyalitas Merek yang telah dibuktikan dengan menunjukkan dan bahwa $F$ hitung yaitu 12,832 . F tabel 0,39 dengan mempunyai nilai sig. yaitu $0,000<(\alpha) 0,05$ Maka $\mathrm{Ho}_{4}$ di Tolak dan $\mathrm{Ha}_{4}$ di Terima yang berarti terdapat hubungan yang positif dan signifikan antar Identitas Merek(XI). Citra Merek (X2), Kepercayaan Merek (X4) terhdap Loyalitas Merek (Y).

5. Pada analisis Koefisien Determinasi atau (Adjusted $R$ Square) yaitu mempunyai nilai 0,264 atau $26,4 \%$ artinya mempunyai kemampuan variabel bebas dalam menjelaskan setiap variabel pada variabel terikat adalah sebesar 26,45 , dan mempunyai sebesar 0,736 atau $73,6 \%$. Yang memiliki Faktor lain ini yang dimaksud tidak diteliti dalam penelitian ini.

\section{SARAN}

Sesuai dengan kesimpulan-kesimpulan sebagaimana tersebut diatas makan dengan ini menyarankan hal-hal sebagai berikut :

I. Kiranya kepada pimpinan perusahaan dapat lebih meningkatkan citra merek dikalangan para pelanggan melalui pelayanan yang lebih bersahabat.

2. Disamping itu pimpinan perlu memberikan pembinaan yang kondusif kepada para karyawan secara berkesinambungan sehingga merek dapat memahami cara-cara pelayananan yang sesuai dengan budaya lokal, sehingga citra merek selalu teringat dihati para pelanggan.

3. Oleh karena itu sangat diharapkan agar para karyawan selalu berinisiatif untuk bersapa, bertatap muka dan berpenampilan yang baik sehingga dapat menumbuhkan kepercayaan para pelanggan terhadap rumah makan waroeng spesial sambal "waroeng ss" dimasa yang akan datang.

4. Dengan demikian dapat dicipta kondisi yang menimbulkan inisiatif para pelanggan untuk selalu kerumah makan waroeng spesial sambal "waroeng ss", maka disarankan agar kondisi yang telah baik ini lebih ditingkatkan lagi dimasa yang akan datang.

5. Kemudian untuk lebih memantapkan loyalitas para pelanggan terhadap merek rumah makan waroeng spesial sambal "waroeng ss", maka peningkatan pelayanan melalui penampilan para karyawan dalam melayani para pelanggan selalu tercipta hal-hal yang yang positif.

\section{E. DAFTAR PUSTAKA}

Sumber Lain :

Ayat Al - Qur'an (Asy-Syu'ara' ayat I8I-184)

Sumber Jurnal :

A. Aaker, David. 20 13. Manajemen pemasaran strategis. Jakarta : Salemba Empat

Ade Jermawinsyah Zebuah. 2018 "Analisis Identitas Merek, Loyalitas Merek, Citra Merek dan Kepercayaan Merek Toyota”. Jurnal Manajemen Pemasaran, Vol. I 2. No. I2,

Aditya Hendrajati, 2016 "PEngaruh Identity Terhadap Brand Loyaly MElalui Brand Image dan Brand Trust Yamaha". Universitas Negeri Yogyakarta

Anjani, Arin. 2017. "Pengaruh Brand Image dan Brand Trust Terhadap Brand Loyalty (Studi Kasus Konsumen Lipstik Revlon di Yogyakarta)”. Skripsi. Yogyakarta. Universitas Negeri Yogyakarta.

Annisa, Mira. 2016. "Pengaruh Citra Merek. Kepercayaan Merek dan Kepuasan Konsumen Terhadap Loyalitas Merek (Studi Kasus pada Pelanggan Pos Indonesia di Fakultas Ekonomi Univeersitas Negeri Yogyakata)". Skripsi. Yogyakarta. Universitas Negeri Yogyakarta

Cindy Franciska Tingkir, (2016). Pengaruh Identitas Merek terhadap Loyalitas Merek melalui Citra Merek dan Kepercayaan Merek Toyota. Jurnal Manajemen Pemasaran, Vol.8, no.2.ISSN : 1907-235X

Danny Alexander Bastian, 2014. Analisa pengaruh citra merek (Brand Image) dan kepercayaan merek ( Brand trust ) terhadap loyalitas merek (Brand Loyality) ADES PT. Ades Alfindo Putra Setia. Jurnal manajemen pemasaran Petra Vol 2, No I, (20l4) I-9 
Dewi Sari, Anggala.2017. "Pengaruh Citra Merek dan Kepercayaan Merek Terhadap Loyalitas Konsumen Memakai Kosmetik Wardah di Kota Padang”. Jurnal Ekonomi Vol. I0. No.2. Uniiversitas Bung Hatta

Elisabet Kristina Dewantari. 2018. "Analisis Citra Merek Dan Kepercayaan Merek Pada Loyalitas Merek Mie Sedap”. Universitas Sanata Dharma.

Mira Annisa. (2016). "Pengaruh Citra Merek, Kepercayaan Merek Dan Kepuasan Konsumen Terhadap Loyalitas Merek Jasa Kurir (Studi Kasus Pada Pelanggan Pos Indonesia di Fakultas Ekonomi Universitas Negeri Yogyakarta)". Skripsi. Yogyakarta, Universitas Negeri Yogyakarta.

Rizan, S. (2012). Pengaruh brand image dan brand trust terhadap brand loyalty teh botol sosro. Jurnal Riset Manajemen Sains Indonesia. Jakarta: Universitas Negeri Jakarta

\section{Sumber Buku :}

Armstrong dan Philip Kotler.2014. Manajemen Pemasaran, Edisi Kesembilan. Jakarta: PT.Indeks Gramedia.

Kotler , P. \& Armstrong, G.2008. prinsip-prinsip pemasaran. Jilid I, edisi I2. Ahli bahasa Benyamin Molan. ( Jakarta:Erlangga.)

Kotler, Philip dan Kevin Lane Keller. 2009. Manajemen Pemasaran Ed. I 3 jilid I \& II. Jakarta : Erlangga

Fandy Tjiptono. (20I4). Strategi Pemasaran. Edisi 3. Yogyakarta: Andi Penerbit.

Freddy Rangkuti. (2004). The Power of Brand. Jakarta: PT. Gramedia Pustaka Utama.

Saiful Bahri,Se,Msa,Akt (2018) Metodologi Penelitian Lengkap. Jakarta.

Sugiyono. (2017). Metode Penelitian Bisnis. Bandung :CV Alfabeta. 